\title{
Do agregado ao pobre-diabo: mudanças e permanências na literatura e na história do Brasil, 1870-1930
}

\author{
From the dependent to the poor-devil: changes and survivals in Brazilian literature and \\ history, 1870-1930
}

Ricardo Russano dos Santos

Doutorando em Letras (Teoria Literária e Literatura Comparada) pela Universidade de São Paulo ricardorussano@gmail.com

\begin{abstract}
Resumen: A figura do agregado é uma importante chave no entendimento da literatura brasileira da segunda metade do século XIX - especialmente do romance a partir da década de 1870. Da mesma forma, o romance de 30 tem na imagem do fracassado (o "pobre-diabo") uma recorrência que chamou a atenção de diversos escritores e críticos da época e posteriores. Este artigo traça um paralelo entre esses dois tipos literários, bem como entre os dois períodos abordados, para entender até que ponto o sujeito de classe média fracassado de 1930 é herdeiro - social e literário - do homem pobre livre dependente do final do século XIX.
\end{abstract}

Palavras-chave: agregado, pobre-diabo, romance.

\begin{abstract}
The "dependent" figure is an important key to undestand Brazilian literature from the last half of the 19th century - specially to understand novel from the last three decades of that century. Similarly, the 1930's decade novel shows repeatedly the figure of the loser (the poor-devil), a recurrence that catch the eye of many writers and critics from then to now. This paper draws a comparison between these two literary types, as well as between the two mentioned periods, in order to understand to what extent the middle class loser from 1930 follows - social and literally - the trace of the poor free man from the late $19 \mathrm{~s}$.
\end{abstract}

Key words: Dependent, poor-devil, novel.

A partir especialmente da publicação dos célebres estudos de Roberto Schwarz (2008a, 2008b) sobre o romance de Machado de Assis, a figura do homem pobre livre, mais especificamente do agregado, passou a ser uma chave de interpretação para a 
literatura do século XIX. Essa figura social típica do desenvolvimento brasileiro, no entanto, é muito anterior à obra machadiana e já aparece representada em romancistas como Bernardo Guimarães, Franklin Távora, Visconde de Taunay e, especialmente, José de Alencar, responsável por ficcionalizar o agregado não apenas no campo, como os autores anteriores, mas também na cidade.

Posteriormente, já no século XX, o romance de 30 será responsável por dar centralidade a outra figura social, a qual também passará a ser vista como chave de interpretação literária: o "pobre-diabo" (PAES, 1988), representante de uma classe média sempre que sempre beira a penúria e que, comumente, ocupa um cargo público de baixa extração e pouquíssima relevância. A relação entre essas figuras não é mera coincidência; apesar de provenientes de períodos distintos, com grandes diferenças entre si, o agregado e o "fracassado" (ANDRADE, 2002: 212) servem como contraponto às ideologias dominantes em seus tempos: o liberalismo do século XIX é subvertido pela sociedade do favor, enquanto o progresso republicano de inícios do $\mathrm{XX}$ cai por terra pela continuidade do paternalismo do século anterior (HOLANDA, 2008). Para entender essa relação, é necessário examinar esses tipos sociais em seus momentos 116 históricos.

A sociedade brasileira do século XIX, de acordo com Emília Viotti da Costa, é marcada, traspassada e regida por uma instituição "que marcou os destinos de nossa sociedade" (COSTA, 2010: 13): a escravidão. De 1808 a 1850, ano em que a Lei Eusébio de Queiroz proíbe de fato o tráfico negreiro, quase 1,5 milhão de escravos foram trazidos ao Brasil, 378 mil só na década anterior à proibição (CARVALHO, 2012) ${ }^{1}$. A centralidade da relação entre senhor e escravo no setor produtivo, bem como a difusão da escravidão entre todas as camadas sociais, farão dessa relação a tônica da sociabilidade brasileira do século $\mathrm{XIX}^{2}$, no campo e na cidade. O senhor de escravos (barão de café em sua versão ao sul, senhor de engenho ao norte, grande capitalista nos centros urbanos) dominará a vida política assim como domina a casa-grande.

Nesse sentido, Ilmar Mattos, em O tempo saquarema, destaca que a função da classe dirigente é reger bem, seja o governo, com suas atribuições políticas, seja a casa, em que deve gerir o trabalho dos cativos (MATTOS, I., 2017: 130). Além disso, o autor,

\footnotetext{
${ }^{1} \mathrm{O}$ grande número de escravos trazidos nos anos que precedem a aprovação da lei deixa entrever que a proibição já era discutida e esperada, fomentando o interesse em trazer cativos para abastecer por bastante tempo as lavouras (ou lucrar com a revenda quando os preços disparassem após a proibição, o que de fato ocorreu).

${ }^{2}$ Tal afirmação não pretende, por exclusão, negar que tal relação se mantenha durante o século XX e ecoe até o Brasil atual; essa herança, entretanto, não é o objeto central deste trabalho.
} 
ao tratar da constituição da sociedade em meados do século XIX, cita o livro Minhas recordações, de Ferreira de Rezende, no qual se apresenta a seguinte categorização para a sociedade brasileira da época: "a dos brancos e sobretudo daqueles que por sua posição constituíam o que se chamava de boa sociedade; a do povo mais ou menos miúdo; e finalmente a dos escravos" (apud MATTOS, I., 2017: 126).

A chave para a distinção dessas classes, de acordo com Ilmar Mattos, repousa nos conceitos de liberdade e propriedade. A escravaria, nesse desenho, não conta nem com liberdade, nem com propriedade - resta-lhe o mundo do trabalho. Os outros dois grupos, por sua vez, contam com liberdade; o que os distingue é a propriedade. A classe dirigente não é apenas proprietária de si mesma, mas também dos escravos. O “povo mais ou menos miúdo", por sua vez, detém a posse sobre si mesmo, mas não é proprietário - ao menos não significativamente e em grande escala - de outrem (MATTOS, I., 2017: 129).

Com base nessa distinção, é possível estabelecer a diferença entre cidadãos ativos (que detêm propriedade e liberdade) e não ativos (que contam apenas com a liberdade). Os últimos "não tinham lugar nem ocupação; não pertenciam ao mundo do trabalho e muito menos deveriam caber no mundo do governo" (MATTOS, I., 2017: 129). Alijados do processo produtivo, esses homens se tornavam agregados, quando alcançavam o favor de um grande proprietário, ou vadios, quando se opunham aos senhores.

Apesar da imobilidade inerente a essa organização social, alguns eventos desencadearam mudanças profundas, ainda que não necessariamente evidentes aos contemporâneos. A década de 1870 representa o canto do cisne da Monarquia brasileira. Com a vitória na Guerra do Paraguai, o ufanismo nacionalista, inexistente antes da guerra, louva o Imperador para com isso exaltar a nação. Além disso, a aprovação da Lei do Ventre Livre, em 1871, representa uma vitória política de D. Pedro II, declaradamente contra a escravidão ${ }^{3}$. Entretanto, esses dois eventos, que expressavam de forma límpida o poder da Monarquia, ao mesmo tempo contribuem para a ascensão de duas camadas sociais que derrubarão o Império em 1889: o exército e os cafeeiros do Velho e Novo oestes paulistas.

Até a Guerra do Paraguai, o Brasil não tinha um exército plenamente formado, o que forçou à ampla convocação de soldados, comumente homens pobres livres ou

\footnotetext{
${ }^{3}$ Já em 1867, em sua Fala do Trono, o Imperador cobrara a erradicação gradual da escravidão.
} 
escravos, enviados para preencher as vagas dos seus senhores e que ganhavam, com isso, a alforria. Terminada a guerra, esses sujeitos voltaram para uma sociedade brasileira ainda pouco dinâmica e sem lugar para eles, uma sociedade de bacharéis beletristas, e não da técnica ou de homens de ação, o que fará com que o exército se torne cada vez mais endógeno, apartado das instituições do Império e crítico destas. ${ }^{4}$

No outro flanco, a aprovação da Lei do Ventre Livre representou um forte cisma entre os senhores do café do Oeste paulista, bem como dos senhores de engenho pernambucanos, e a Coroa, o que levou à disseminação de ideias republicanas e de críticas ao centralismo monárquico. Na região de Campinas, bem como no sul do país, no Recife e diversas outras províncias, além do republicanismo, um ideal federativo se destacava, marcado pela crítica veemente à ingerência da Corte sobre o resto do país e, consequentemente, pelo ataque à figura do Poder Moderador, que, na visão de um crítico célebre, se tornara Poder pessoal (ALENCAR, 2008). Um liberalismo absolutamente elitista e demofóbico animava essas elites - especialmente a paulista -, enquanto as camadas médias ilustradas defendiam um liberalismo muito mais radical e amplo, e os militares - mais influentes na Corte e no Rio Grande do Sul - tendiam ao positivismo e ao jacobinismo, também presente nas camadas médias urbanas. A união de interesses entre essas forças lançou por terra o Império em 1889, um ano depois que a Abolição da Escravatura corroeu o resto de apoio que a Monarquia ainda angariava entre camadas senhoriais importantes, mas já decadentes, como os senhores do café do Vale do Paraíba e do açúcar do Recôncavo Baiano.

Ressaltar a importância da Guerra do Paraguai e da Lei do Ventre Livre, entretanto, não significa excluir as mudanças que ocorriam nos parâmetros literários do período, entre outras coisas porque, se é verdade, como se ressentiam os oficiais e engenheiros do exército, que a política e a vida social do Brasil Império eram centrados no arrivismo social de bacharéis beletristas, a literatura ocupava lugar de destaque entre

\footnotetext{
${ }^{4}$ Ao tratar do período entreguerras europeu, Eric Hobsbawm destaca o grande contingente de soldados rasos que voltava da guerra com um sentimento profundamente anticivil; a relação de camaradagem entre combatentes aliava-se ao trauma da experiência da guerra de trincheiras e fazia com que esses soldados só respeitassem quem vivera aquilo e, especialmente, desprezassem quem não participara: especialmente mulheres, crianças e idosos. Essa camaradagem se converteu facilmente em sentimento belicista e ódio a todo pacifismo, identificado especialmente nos partidos de esquerda, críticos da guerra e vistos, especialmente na Alemanha, como traidores da nação. Como lembra Hobsbawm, "esses rambos da época eram recrutas naturais da direita radical", engrossando as fileiras nazifascistas. Cf. HOBSBAWM, 1995: 128. Parece acontecer algo parecido com esses soldados brasileiros que voltavam de uma guerra em que lutaram lado a lado brancos, mulatos, negros livres e escravos para um país escravocrata. Incensados em um primeiro momento, mas esquecidos e sem lugar nessa sociedade, os membros do exército se tornarão cada vez mais críticos do establishment brasileiro, inclusive em oposição à Marinha, que sempre fora respeitada e vista como uma forma de ascensão ou manutenção do status social.
} 
as camadas letradas nacionais. E o que se percebe ao observar a literatura brasileira das últimas décadas do Império confirma tal importância.

A década de 1870 é importante para a cultura brasileira por marcar a ascensão de novas ideias, com destaque para teorias cientificistas, influenciadas pelas mudanças na vida intelectual europeia. A mesma década de 1870 vai presenciar o aparecimento de novos autores, polêmicas literárias e, especialmente, obras que traziam em seu bojo mudanças no ideal do que seria a boa prosa de ficção. Em 1871, Távora enviará para publicação na Corte suas Cartas a Cincinato, conjunto de missivas dedicadas a mostrar o que ele avaliava como a flagrante decadência do então grande romancista brasileiro José de Alencar - e cobrar-lhe uma escrita mais preocupada em reconstruir de forma bela o real do que de transformá-lo por meio da livre imaginação. Era esse voo livre da imaginação romântica que se via, na década de 1870, sob ataque, seja explícito, como nas Cartas de Távora, seja implícito nas obras literárias que surgiam, inclusive nas do próprio Alencar.

Esse movimento em parte já era perceptível em finais da década de 1860; a poesia declamatória e engajada suplantará o ultrarromantismo e a ironia nascidos na Academia de Ciências Sociais e Jurídicas de São Paulo. Tal poesia atacará principalmente a escravidão, chaga cada vez mais vergonhosa para o país, e a Monarquia, em prol de uma república projetada a partir de um liberalismo radical. Tanto na poesia quanto na prosa, o indianismo - que se tornara quase uma literatura oficial do Império ${ }^{5}$ - vai cedendo lugar a outras temáticas na representação do que seria a identidade (e a vida) nacional: por um lado, o romance urbano vai se tornando mais complexo, aumentando seu escopo de personagens em prol de uma melhor representação da vida cotidiana nas cidades brasileiras, especialmente a Corte; por outro, surge uma vertente de obras que retratam as vastas extensões do interior do país e a vida nesses lugares, provavelmente a mais profícua e variada vertente da literatura brasileira, a que chamamos regionalismo ${ }^{6}$.

Mesmo no Romantismo, o regionalismo nasceu do "amor ao documento" (BOSI, 2007: 149), canalizando o interesse histórico dos autores para a pesquisa exaustiva dos arquivos e ensaios publicados nos diversos institutos históricos distribuídos pelo país para, a partir disso, embasar seus romances. Essa necessidade de

\footnotetext{
${ }^{5}$ Vale lembrar que um importante jornal monarquista da Corte, quando da vitória brasileira na Guerra do Paraguai, estampou em sua capa uma charge de D. Pedro II paramentado como chefe indígena.

6 A despeito de a aplicação do conceito de "regionalismo" a obras do século XIX suscitar alguns questionamentos, optou-se por usá-lo aqui para facilitar o entendimento.
} 
uma verossimilhança externa, já existente no Romantismo, se aprofundará conforme as novas ideias estéticas e científicas aportarem no país, naquilo que Silvio Romero chamou de "um bando de ideias novas" (apud ALONSO, 2002). A necessidade de verossimilhança externa, no romance urbano e regionalista, fará com que tipos sociais marginais nas obras até então, ou mesmo ausentes, como agregados e escravos, ganhem enfoque. Além disso, e mais importante, nessa virada realista as relações entre as classes sociais passam da vassalagem respeitosa entre diferentes, tão comum nas obras indianistas e regionalistas alencarianas, para o jugo dos mais fortes sobre os mais fracos, seja através de relações desiguais de poder no compadrio - como é o caso do favor -, seja através da violência aberta, na relação senhor/escravo. Essa tomada de consciência na literatura, ou, melhor dizendo, essa abertura da literatura a um realismo que buscava analisar e apresentar as relações sociais com o máximo de fidelidade, marca uma passagem da construção histórica de uma nação nascente através da mitificação para uma crítica construtiva daquilo que se via, em prol de um projeto estético e social (geralmente republicano e abolicionista).

No século XX, parece haver uma abertura do escopo da matéria literária em alguns pontos parecida com essa ocorrida em torno da década de 1870. O Modernismo de 22 , em sua procura do "eterno presente", reconstruía a história brasileira através da mitificação, de uma síntese baseada na dicotomia entre modernidade (a São Paulo industrial) e primitivismo (a antropofagia, o Macunaíma etc.); já em 1930, todas aquelas populações marginalizadas - seja socialmente, seja como matéria literária - ganham espaço: sertanejos pobres, proletários brutalizados pelo trabalho e pela desterritorialização causada pela migração forçada e desestruturada, prostitutas ou jovens pobres aniquiladas pelo jugo patriarcal. Mas nessa abertura à realidade corrente externa à literatura que ocorria em 1930 - um empuxo ao realismo em alguns pontos parecido com o que ocorrera na segunda metade do século XIX - será o funcionário público membro de uma classe remediada à beira da pobreza que se tornará o narrador em primeira pessoa por excelência.

Não pretendemos aqui simplificar a prosa da década de 30; se há, de fato, um momento literário profícuo e um debate artístico pujante nesse período em torno da representação da realidade no romance, tal representação não pode ser tratada de forma generalizante e homogênea, pois, no escopo do que se convencionou chamar de "Romance de 30", há, pelos menos, duas tendências principais divergentes: o romance social e o romance psicológico. Entre essas duas correntes principais há divergências de 
enfoque e, geralmente, de visão política, ainda que dentro de cada tendência haja também ideologias diversas. ${ }^{7}$ Tampouco o romance das décadas de 1870 e 1880 pode ser homogeneizado; entretanto, o que buscamos aqui é encontrar as convergências no movimento geral percebido em cada um dos momentos literários tão distintos entre si. Para isso, essas figuras ficcionais que se repetem nos romances de cada um dos períodos - o agregado e o pobre-diabo - fornecem uma pista interpretativa, deixando entrever na sociedade brasileira do século XX, já plenamente capitalista, heranças das relações presentes no período escravista do Brasil.

As mudanças literárias do período de transição do Romantismo ao Realismo, bem como a passagem do Modernismo de 22 ao de 30, deixam entrever um abandono da busca pela construção de uma identidade nacional a partir do mito, de um historicismo profundamente preocupado em identificar os elementos da formação brasileira, para uma premência de interpretar e apresentar o "real", o que também aguçará a consciência histórica dos escritores, mas em prol do entendimento da situação atual do país como decorrência do desenvolvimento histórico local. No primeiro caso dos modernistas de 22 e especialmente dos românticos (com exceção do ultrarromantismo) - há uma visão positiva na criação literária a partir do conhecimento histórico, uma visão engajada na capacidade criadora e revolucionária da literatura sobre o meio social local; esse mesmo espírito, talvez de forma mais contida, guiará vários escritores do Realismo e da literatura de 30, mas será uma sensação acre com relação ao próprio país e às suas possibilidades que guiarão a busca pela história nesse segundo grupo. Unido a essa visão negativa do país há um mal-estar pessoal de tais escritores, o que dá a seus romances e poemas um tom mais pungente que acaba por destacar a melancolia como o sentimento nacional por excelência (um poema como "A flor e a náusea" ou um romance como Angústia expressam perfeitamente essa simbiose entre público e privado). ${ }^{8}$

\footnotetext{
${ }^{7}$ Sobre a heterogeneidade do romance de 30 , bem como sobre o movimento interno à década que parece se iniciar com a preponderância do romance social e seguir paulatinamente à preponderância do romance psicológico, ver: BUENO, 2006. Especialmente a Introdução, mas também a primeira parte, intitulada "Dois problemas gerais".

${ }^{8}$ Vale lembrar que no século XIX e começo do XX a grande questão dos pensadores nacionais se dava em torno da melancolia como sentimento nacional (por que os brasileiros, especialmente do interior, eram tão melancólicos?). Desde um Teodoro Sampaio viajando pelo Rio São Francisco até Euclides da Cunha e Sílvio Romero, esse questionamento era contínuo. Não cabe ao escopo deste trabalho discutir quando isso mudou, mas a propaganda do Estado Novo em torno do samba como microcosmo artístico nacional bem como a modernidade bossa-nova de Juscelino Kubistchek podem ajudar a encontrar o período de mudança, principalmente reforçando a centralidade das grandes cidades na formação da identidade nacional.
} 
Ainda que o agregado não ganhe voz como narrador-personagem na segunda metade do século XIX, tal figura passa claramente do pano de fundo das histórias para o centro da narrativa (tenha-se em mente, por exemplo, o romance machadiano de 1878 Iaiá Garcia). Além disso, as relações de favor são representadas não mais a partir da lógica do respeito mútuo entre suserano e vassalo, de inspiração medieval (como em $O$ Guarani e $O$ sertanejo, de Alencar), ou como rede familiar de proteção em uma sociedade católica (como nos primeiros romances machadianos), mas como base da vida sociocultural, impedindo o desenvolvimento no Brasil de um regime liberal de molde europeu em que as liberdades individuais e o trabalho livre regessem a vida pública. Como lembra Roberto Schwarz em sua análise de Iaiá Garcia, até "o dinheiro neste romance não tem existência autônoma, e aparece direta e 'naturalmente' vinculado ao poder paternalista" (SCHWARZ, 2008a: 165).

Especialmente nos romances da maturidade de Machado de Assis, o paradoxo entre liberalismo no discurso e sociedade do favor na prática - com a mácula vergonhosa da escravidão - não apenas se tornará explícito como será o fator organizador do romance, criado em torno de uma cultura do "capricho" e com uma forma baseada na "dissonância" e volubilidade do narrador (SCHWARZ, 2008b: 193). Nessa cultura do capricho a lógica da organização social se dá a partir do livre-arbítrio de uma única classe, a senhorial, que controla de forma direta e inapelável o destino de seus escravos, mas também o dos homens livres pobres, dependentes do favor desses senhores, seja financeiramente, seja como proteção (nas cidades, a primeira forma será a mais comum; no campo, a segunda).

O arbítrio senhorial regia a vida pública brasileira, mas era a ideologia liberal que regia a vida cultural e política, o que produzia uma dissonância que acabava por criar para o intelectual e artista brasileiro uma incerteza e dubiedade paralisantes que empobreciam muito a reflexão acerca da realidade local nos romances. Entretanto, quando o autor conseguia superar esse bloqueio, o resultado era uma visão profunda não apenas da realidade local, mas do que ela significava em relação à ideologia importada. ${ }^{9}$ O "tic-tac das conversões e reconversões de liberalismo e favor" (SCHWARZ, 2008a: 30) no solo nacional servia à classe dirigente, que a um só tempo podia arvorar-se parte

\footnotetext{
${ }^{9}$ Roberto Schwarz sugere em seu célebre "As ideias fora do lugar" que essa percepção profunda e cética a respeito do liberalismo, perceptível no Machado de Assis da maturidade, também rege a literatura russa do XIX; lá, como cá, a "síndrome de vira-lata" por perceber as amarras locais que impossibilitavam o progresso aos moldes da Europa ocidental acabavam fazendo com que o romancista - quando conseguia se desvencilhar da armadilha do pitoresco e do nacionalismo declamatório e tacanho - percebe-se o que havia de contraditório no liberalismo mesmo em seu centro difusor.
} 
do progresso liberal europeu no campo cultural e político e, ainda assim, manter seus privilégios de uma sociedade quase estamental em que seus interesses estão garantidos, contra as incertezas e austeridade da livre-concorrência burguesa. Exemplo máximo dessa relação desequilibrada entre estrutura de uma sociedade do favor e superestrutura liberal em nossa literatura é Brás Cubas, herdeiro que se orgulha da "fortuna de não comprar o pão com o suor do meu rosto" (ASSIS, 2008: 263), mas que, ao entregar uma moeda ao amigo de infância decaído à miséria - Quincas Borba -, repete o ideário liberal ao afirmar estar nas mãos de Quincas a possibilidade de ganhar muitas outras, através do trabalho. Ainda que a lição moral revele a contínua hipocrisia de Brás Cubas - receita o trabalho aos outros, mas se orgulha de não precisar trabalhar -, ela indica um contrassenso mais profundo: Brás, herdeiro e membro da camada dirigente, não precisa nem nunca trabalhará, pois sua posição social não depende nem é fruto de seu trabalho, mas da estrutura social que o precede; já os homens pobres livres, seguindo a ideologia dominante, dependiam de seu próprio trabalho para ascender socialmente, ou seja, eram pobres não porque dependiam do favor da classe senhorial e estavam alijados do setor produtivo principal, majoritariamente escravista, mas por falta de esforço e/ou talento. A ideologia liberal europeia se adaptava à realidade local, não para promover as reformas necessárias à sociedade da livre-concorrência, mas sim para garantir a justeza da imobilidade social reinante.

O fim da escravidão, a maciça imigração de europeus a partir de finais de $1870 \mathrm{e}$ o desenvolvimento econômico do período republicano tornaram a sociedade brasileira mais complexa e dinâmica mantendo, entretanto, diversas marcas do Império - a começar pelo poder dos grandes proprietários rurais e da violência no campo. Entre o otimismo em um novo Brasil moderno marcado pela república integradora e o pessimismo de elites que viam no convívio público das cidades o risco da baderna e da dissolução moral; entre o otimismo de intelectuais assimilados e engenheiros que reconstruíam as grandes cidades a partir do modelo francês, de um lado, e artistas e intelectuais céticos que percebiam a parca cidadania das camadas mais baixas, excluídas inclusive espacialmente nos centros urbanos, de outro, além do profundo esquecimento em que viviam as populações interioranas, formava-se um país desigual: “de um lado, a cidade, definida pela indústria, pelas oportunidades de trabalho, pelo mercado, mas também por uma política de exclusão e de distanciamentos. De outro lado, os 'demais Brasis', perdidos nos sertões, longínquos na realidade e na imaginação, ou nas florestas fechadas" (SCHWARCZ, 2012: 24). 
Alguns escritores, como Lima Barreto, João do Rio e Euclides da Cunha, se baterão com essas realidades excluídas da visão dos progressistas de então, apontando no desenvolvimento do período seu caráter alienado da realidade do país ou propositalmente excludente social e racialmente; outros autores, como Simões Lopes, Coelho Neto e Valdomiro Silva, terão "uma visão do mundo estática quando não saudosista” (BOSI, 2007: 324), às vezes alienada e, em geral, pitoresca da realidade brasileira, descrevendo a vida no interior do país a partir de uma combinação de estereótipos, dramalhões e beletrismo.

Essa verborragia tradicionalista e vazia, "limitada" e "incapaz de desvencilhar-se daquele conceito mimético de arte herdado ao Realismo naturalista” (BOSI, 2007: 327), será fortemente criticada pelos modernistas de 22, ávidos em mudar a literatura local e reinterpretar sua história cultural a partir do misto de primitivismo e frenesi moderno que aportava da Europa através de revistas, livros ou viagens. A capital por excelência desse movimento será a São Paulo das primeiras décadas do século XX, com seu crescimento urbano vertiginoso baseado no contato entre uma população local provinciana e imigrantes (e migrantes) de várias partes do mundo. $\mathrm{O}$ incremento urbano se dará também pelo desenvolvimento industrial nos entornos da cidade, criando uma massa de proletários como o Brasil ainda não tinha presenciado, bem como uma elite industrial urbana que dividirá espaço com grandes produtores de café absenteístas. O encontro do "dinheiro grosso" com as massas de trabalhadores industriais fará de São Paulo (e, em menor escala, da capital Rio de Janeiro e outras capitais pelo país) uma cidade próxima do arcabouço europeu do que se via como uma urbe moderna: largas avenidas, teatros e cafés luxuosos, bondes e carroças disputando as ruas, iluminação pública e enormes greves trabalhistas abafadas com extrema violência do poder público.

O Modernismo será produto direto dessa efervescência das grandes cidades brasileiras, procurando responder artisticamente ao descompasso claro entre uma sociedade nova e uma República Velha. Num primeiro momento, em 22, essa resposta será mais voltada à recusa da tradição que precedia os autores modernistas - o regionalismo do início do século XX, o Parnasianismo e o Realismo/Naturalismo - e à reinterpretação (e refundação) da história do país a partir das novas ideias que aportavam no Brasil. Essa reinterpretação se dará através de dicotomias entre primitivismo e modernidade (do índio ao operário, da selva à metrópole etc.), num movimento que privilegiava o mito à história e à análise social, a ponto de um membro dessa primeira fase do Modernismo chamar a si e seus companheiros de "inconscientes" 
(ANDRADE, M., 2002: 209), afirmando a incapacidade desse grupo de autores de mudar neles mesmos seu desinteresse "diante da vida contemporânea", a ponto de tornarem-se "abstencionistas abstêmios" (ANDRADE, 2002: 278).

Tal inconsciência se dissipa paulatinamente e, na década de 30, mesmo participantes da Semana de Arte Moderna de 22 parecem ampliar seu escopo artístico, movimento próximo ao ocorrido na década de 1870; como parte desse movimento, o agregado descrito em terceira pessoa, típico dos romances do final do século XIX, cede espaço ao funcionário público remediado, muitas vezes narrador do romance ou eu lírico do poema.

Os últimos anos do século XIX e as primeiras décadas do século XX no Brasil combinam uma série de fatores - "crise da economia agrário-exportadora, desenvolvimento do setor público, entrada de volumosa população emigrante e o crescimento urbano" (SCHWARCZ, 2012: 78) - que promovem um incremento tanto do número de profissionais liberais quanto de funcionários públicos. Além disso, no interior, "o coronel republicano, enfraquecido com a perda da autoridade senhorial após a Abolição, precisava agora do poder de administrar as benesses e o poder repressivo do Estado" (MATTOS, 2012: 108), o que dava mais poder à população rural pobre, enquanto, nos centros urbanos, via-se a disseminação de sindicatos e partidos operários. Essas mudanças não foram de forma alguma suficientes para tornar a república brasileira inclusiva, mas representam uma tomada mínima de poder por parte das camadas pobres no Brasil: sem a escravidão, esses homens pobres livres eram necessários ao setor produtivo nacional, o que obrigava a classe senhorial a usar da violência estatal via força pública, mas também da negociação através de melhorias sociais (e cargos na administração pública) para manter a estabilidade social e a mão de obra disponível.

O funcionário público de baixa extração representa para o romance de 30 o que o agregado representava para as últimas décadas do século XIX por serem tais personagens a figura-chave da cultura nesses períodos. Como lembra Roberto Schwarz, a base econômica do Brasil imperial se dava na relação senhor/escravo; entretanto, a vida política e cultural era baseada no favor, ou seja, na relação senhor/agregado. Essa relação de favor indicava a extensão do poder senhorial e o quão tacanha e dissonante era a vida social brasileira: baseada no liberalismo europeu, a vida política e social no Brasil não era livre, mas dependente das ingerências e caprichos de uma classe dirigente a que nada estava fora do alcance, nem mesmo a dignidade humana de seus 
compatriotas. Na década de 30, o sujeito de classe média, geralmente funcionário de repartição, livre da miséria, mas sempre às voltas com a penúria, representa boa parte da intelectualidade, dos letrados que enchem os cafés e as livrarias; esses homens são livres, assalariados e instruídos, seriam eles, em tese, os cidadãos típicos de uma democracia liberal, sempre em busca de seus próprios interesses e felicidade. $\mathrm{Na}$ prática, são homens instruídos o suficiente para se darem conta do descompasso entre a liberdade aparente e o Estado excludente: capazes de perceber que o compadrio ainda rege o funcionalismo público e a política, que a violência estatal rege a vida pública ${ }^{10} \mathrm{e}$ que o racismo impede a inclusão de largas faixas da população. Mais do que capazes de entender as relações de compadrio, os personagens dos romances de 30 - Belmiro, Abdias, Naziazeno e o em tudo representativo Luís da Silva - imiscuem-se em tais relações para garantir a própria subsistência. Inseridos nessa relação que lhes faz ao mesmo tempo desprezar o trabalho - "ocupação estúpida e quinhentos mil réis de ordenado" (RAMOS, 2011: 25) - e a si mesmos, tais personagens diversas vezes serão capazes de perceber profundamente seu lugar na sociedade. Ao descrever o café que frequenta ao menos uma hora por dia todos os dias, por exemplo, Luís da Silva acaba por apresentar sua posição baixa na hierarquia social:

Há o grupo dos médicos, o dos advogados, o dos comerciantes, o dos funcionários públicos, o dos literatos. [...] Naquele espaço de dez metros formam-se várias sociedades com caracteres perfeitamente definidos, muito distanciadas. A mesa a que me sento fica ao pé da vitrina dos cigarros. É um lugar incômodo [...] Contudo, não poderia sentar-me dois passos adiante, porque às seis horas da tarde estão lá os desembargadores (RAMOS, 2011: 36; grifo nosso)

Isso depois de apresentar longamente, através de suas digressões, o caminho de decadência familiar que o levou à miséria, até que conseguisse uma vaga em repartição pública em Maceió, depois de um longo percurso "gastando sola pelas repartições", período repleto de "indignidades, curvaturas, mentiras, na caça ao pistolão" (RAMOS, 2011: 40).

O intelectual de classe média da década de 30 é um sujeito representativo culturalmente, mas não é membro de uma classe ampla e organizada o suficiente para

\footnotetext{
${ }^{10}$ A célebre frase atribuída a Washington Luís - "a questão social é questão de polícia" - é um bom indicativo de como a República Velha lidava com as questões sociais.
} 
de fato demandar mudanças na estrutura social brasileira. Tais mudanças teriam que ser tão profundas quanto eram os problemas em um país em que a maior parte da população vivia na miséria e o Estado republicano era organizado por e para os interesses dos grandes proprietários. O Brasil vivia o florescimento de movimentos políticos urbanos, mas também, no Estado Novo, o recrudescimento da censura e prisão de opositores. ${ }^{11}$ Oprimidos entre uma classe alta - com quem dividiam muitas vezes os espaços públicos, os mesmos parâmetros culturais e geralmente os interesses pessoais - e as camadas baixas - a quem diversas vezes admiravam, pouquíssimas vezes compreendiam e com quem compartilhavam dos mesmos anseios por mudanças -, os intelectuais das primeiras décadas do século XX vão compartilhar com seus personagens do imobilismo que os marca.

O pobre-diabo do romance de 30 viverá em tese numa sociedade da "carreira aberta ao talento", livre das amarras da escravidão e do favor a que estava preso o agregado no século XIX; na prática, entretanto, também esse personagem de classe média dependerá do compadrio e do favor, das boas relações sociais para garantir seu sustento, comumente em uma repartição pública. A liberdade do funcionário público das primeiras décadas do século XX terá muito de aparente, como a do homem livre pobre do século XIX, mas, ainda assim, o fim da escravidão e o incremento da vida urbana darão mais autonomia ao primeiro. Essa autonomia será o suficiente para desenvolver nas cidades brasileiras do período um público leitor maior do que o usual, especialmente no que se refere à leitura de obras nacionais, impulsionando e dinamizando o meio cultural; será também suficiente para dar voz àqueles que apareciam pouco na literatura brasileira ou que, quando apareciam, eram alvo de fetichismo ou indiferença. Não será o suficiente, entretanto, para retirar as amarras do desenvolvimento nacional, que manterá no período - e depois - um caráter elitista e mesmo demofóbico, por isso a figura do fracassado tomará o protagonismo dos romances: um sujeito capaz de refletir, mas não de agir.

\section{Fontes}

ALENCAR, José de (2008). Cartas em favor da escravidão. Org. de Tâmis Parron. São Paulo: Hedra.

\footnotetext{
${ }^{11}$ Diversos intelectuais e artistas sentiram na pele tal recrudescimento da violência estatal, seja através de prisões arbitrárias, como as de Graciliano Ramos e Monteiro Lobato, ou da censura de diversos livros, desde os exemplares incinerados de Capitães da areia, de Jorge Amado, e Menino do engenho, de José Lins do Rego, até o infanto-juvenil Reinações de Narizinho, de Monteiro Lobato.
} 
ANDRADE, Carlos Drummond de (2012). Antologia poética. São Paulo: Companhia das Letras.

ANDRADE, Mário de (2002). Aspectos da literatura brasileira. 6. ed. Belo Horizonte: Editora Itatiaia.

ANJOS, Cyro dos (2006). O amanuense Belmiro. São Paulo: Globo.

ASSIS, Machado de (2008). Memórias póstumas de Brás Cubas. São Paulo: Editora Globo.

RAMOS, Graciliano (2011). Angústia. Rio de Janeiro: Record.

TÁVORA, Franklin (2011). Cartas a Cincinato: estudos críticos por Semprônio. Org. de Eduardo Vieira Martins. Campinas: Editora da Unicamp.

\section{Referencias Bibliográficas}

ALONSO, Angela (2002). Ideias em movimento: a geração 1870 na crise do Brasil Império. São Paulo: Paz e Terra.

BOSI, Alfredo (2007). História concisa da literatura brasileira. 44. ed. São Paulo: Cultrix.

BUENO, Luís (2006). Uma história do romance de 30. São Paulo: Edusp; Campinas: Editora da Unicamp.

CARVALHO, José Murilo de (2012). “As marcas do período". In: História do Brasil nação: 1808-2010 - volume 2: a construção nacional, 1830-1889. Rio de Janeiro: Objetiva.

COSTA, Emília Viotti da (2010). Da senzala à colônia. 5. ed. São Paulo: Editora Unesp.

HOBSBAWM, Eric (1995). Era dos extremos. 2. ed. 46. reimpr. São Paulo: Companhia das Letras.

HOLANDA, Sérgio Buarque de (2008). Raízes do Brasil. 26. ed. 30. reimpr. São Paulo: Companhia das Letras, 2008.

MATTOS, Hebe (2012). "A vida política". In: SCHWARCZ, Lilia Moritz (Coord.). História do Brasil nação: 1808-2010 - volume 3: a abertura para o mundo, 18891930. Rio de Janeiro: Objetiva.

MATTOS, Ilmar Rohloff (2017). O tempo de saquarema: a formação do Estado imperial. 7. ed. São Paulo: Hucitec, 2017, pp. 85-132.

PAES, J. P. 1998). O pobre diabo no romance brasileiro. Novos Estudos, São Paulo, n. 20, pp. 38-53.

SCHWARCZ, Lilia Moritz (2012). "As marcas do período"; "População e sociedade". In: História do Brasil nação: 1808-2010 - volume 3: a abertura para o mundo, 1889-1930. Rio de Janeiro: Objetiva, pp. 19-34.

SCHWARZ, Roberto. (2008a). Ao vencedor as batatas. 5 ed. 4. reimpr. São Paulo: Duas Cidades; Editora 34.

(2008b). Um mestre na periferia do capitalismo. 4 ed. 3. reimpr. São Paulo: Duas Cidades; Editora 34.

Artigo recebido em 10 de março de 2019.

Aprovado em 20 de maio de 2019.

DOI: 10.12957/intellectus.2019.40666 